\title{
Effects of the Volatile Anesthetic Agents on Sinus Node Function and Atrioventricular Conduction in Dogs: A Comparison With Chloralose Anesthesia
}

\author{
Niall C.T. Wilton, MRCP, FFARCS, Charles B. Hantler, MD, Steven N. Landau, MD, Lawrence O. Larson, MD, \\ and Paul R. Knight, MD, PhD
}

\begin{abstract}
The effects of equipotent concentrations (1.5 times minimum alveolar concentration) of the inhalational agents halothane, enflurane, and isoflurane on sinus node function, and atrioventricular (A-V) conduction and refractoriness were compared with chloralose anesthesia in $\mathbf{4 9}$ mongrel dogs. Sinus node function was assessed using corrected sinus node recovery time. Atrial-His and His-ventricular conduction times were measured at paced heart rates of 150,180 , and 200 beats/min, and $A-V$ refractoriness was assessed by Wenckebach periodicity. There was no evidence that sinus node function was impaired by any of the inhalational agents. Enflurane anesthesia was associated with a significant prolongation of
\end{abstract}

A N UNDERSTANDING of the effects of the three commonly used inhalational agents, halothane, isoflurane, and enflurane, on cardiac electrophysiology is important in order to help explain and treat dysrhythmias that may occur when these agents are used during anesthesia. Although changes in cardiac conduction may not often be apparent when these agents are used alone, the potential exists for interactions with other cardiac depressant drugs, particularly the calcium channel blockers ${ }^{1-3}$ and beta-blockers. ${ }^{4}$

Previous experimental work has documented that in vitro, halothane, enflurane, and isoflurane depress sinus node function similarly when equipotent concentrations are compared. ${ }^{5}$ Markedly different responses in heart rate have been seen, however, when the drugs are studied clinically. ${ }^{6}$ There are no previous reports that have examined sinus node function with the different inhalational agents in an intact animal model.

Reported changes of atrioventricular (AV) conduction using inhalational agents have varied according to the model used. Previous

From the Department of Anesthesiology, University of Michigan Hospitals, Ann Arbor.

Address reprint requests to $\mathrm{Dr}$ Niall C.T. Wilton, Department of Anesthesiology, University of Michigan Hospitals, 1500 Medical Centre Drive, Ann Arbor, MI 48109.

(C) 1988 by Grune \& Stratton, Inc.

0888-6296/88/0202-0011\$03.00/0
atrial-His conduction at paced heart rates of 180 and 200 beats/min when compared to chloralose anesthesia and the other two inhalational agents $(P<.001)$. Atrioventricular refractoriness was impaired by enflurane $(P<.001)$ and halothane $(P<.05)$, but not isoflurane, when compared with chloralose anesthesia. Ventricular-His conduction was not altered by any of the agents. The authors conclude that enflurane is associated with a greater impairment of $A-V$ conduction and refractoriness than halothane or isoflurane, and that these changes are related to the anesthetic agent .and not the anesthetic state.

(c) 1988 by Grune \& Stratton. Inc.

work with inhalational agents comparing increasing anesthetic levels of a particular agent found prolongation of $\mathrm{A}-\mathrm{V}$ conduction with halothane $^{7}$ and enflurane, ${ }^{8}$ but not with isoflurane. ${ }^{9}$ More recent work by Atlee et al $^{10}$ comparing conscious and anesthetized states using chronically instrumented animals demonstrated isoflurane to be the least depressant of the inhalational anesthetics, while enflurane and halothane produced equal depression of $\mathrm{A}-\mathrm{V}$ conduction times. They also concluded that the depression of myocardial conduction observed was probably due to the anesthetic state and not to increased levels of the anesthetic per se. ${ }^{10}$

The purposes of this experiment were to: (1) Investigate the effects of the inhalational agents on $\mathrm{A}-\mathrm{V}$ conduction and $\mathrm{A}-\mathrm{V}$ node refractoriness in the anesthetized animal, and to compare these effects to chloralose anesthesia, which does not alter A-V function, ${ }^{11}$ and (2) examine the effects of the inhalational agents halothane, enflurane, and isoflurane on sinus node function in an intact model.

\section{METHODS}

\section{Preparation}

Unpremedicated mongrel dogs of either sex (weight range, 8 to $15 \mathrm{~kg}$ ) were divided into four groups, each anesthetized with a different anesthetic agent. Dogs in group $1(n=12)$ were anesthetized with intravenous chloralose, using $120 \mathrm{mg} / \mathrm{kg}$ for induction and $50 \mathrm{mg} / \mathrm{kg} / \mathrm{h}$ for maintcnance. This group acted as the control group. The other dogs were anesthetized with one of the inhalational agents halo- 
thane, enflurane, or isoflurane, and maintained throughout the experiment at a level of 1.5 times the minimum alveolar concentration (MAC) for that agent. Group $2(n=12)$ animals were anesthetized with $1.3 \%$ halothane (MAC = $0.87 \%)$, group $3(n-13)$ were anesthetized with $3.3 \%$ enflurane (MAC $=2.2 \%$ ), and group $4(n=12)$ were anesthetized with $2.3 \%$ isoflurane (MAC $=1.5 \%$ ). ${ }^{12}$ End-tidal anesthetic concentrations were measured using a Perkin-Elmer Model 1100 medical gas analyzer (Pomona, CA). No muscle relaxants or other drugs were administered to the dogs. All dogs underwent endotracheal intubation and were ventilated using a Bain circuit with a fresh gas flow of $3 \mathrm{~L} / \mathrm{min}$ of air and oxygen.

After induction of anesthesia, femoral artery and vein catheters were inserted. Arterial pressure was measured using Gould-Statham pressure transducers and recorded on a Gould ES-1000 recorder (Cleveland). A quadripolar electrode catheter with an interelectrode distance of $10 \mathrm{~mm}$ was inserted via the right external jugular vein and positioned such that the proximal electrode pair were in the high right atrium (to allow atrial pacing) and the distal electrode pair were used for recording of the atrial electrogram. A bipolar catheter was inserted via the left internal carotid artery and advanced toward the root of the aorta until optimum Hisbundle recordings were obtained as displayed on an oscilloscopc. A right thoracotomy was then performed exposing the heart to allow bipolar plaque electrodes to be sutured to the right atrium and the apex of the right ventricle to deliver extra stimuli for use during further experimentation on the dogs. The ECG, atrial electrogram, and His-bundle electrogram were continuously displayed using a Tektronix Digitalizing Oscilloscope (Beaverton, OR). Intermittent recordings of the above waveforms and blood pressure were made at intervals during the experiment using a multichannel recorder (Gould ES-1000) filtered at 30 to $200 \mathrm{~Hz}$ to allow calculation of the information presented below (Fig 1).

All dogs were ventilated to normocarbia by adjusting the tidal volume to maintain arterial $\mathrm{PaCO}_{2}$ within the range of 35 to $40 \mathrm{mmHg}$. The dogs were hydrated using lactated Ringers solution at $2 \mathrm{~mL} / \mathrm{kg} / \mathrm{h}$ following a loading dose of 5 to $10 \mathrm{~mL} / \mathrm{kg}$. Esophageal temperature was maintained between 36 and $38^{\circ} \mathrm{C}$ using an infrared heater as necessary. Arterial blood gases including $\mathrm{pH}$, plus sodium and potassium, were measured at intervals during the experiment and maintained within the physiologic range. The $\mathrm{pH}$ was maintained between 7.35 and 7.45 using sodium bicarbonate as required ( 0 to $30 \mathrm{mEq} / \mathrm{h}$ ), and the serum potassium between 3.5 and $4.5 \mathrm{mmol} / \mathrm{L}$ by potassium infusion $(0$ to $12 \mathrm{mEq} / \mathrm{h}$ ). All dogs were allowed to stabilize for 30 minutes after the thoracotomy before the experimental procedure was commenced.

\section{Electrophysiologic Measurements}

The following electrophysiologic measurements were made: Corrected sinus node recovery time, atrial-His (A-H) interval with the animals atrially paced at 150,180 , and 200 beats /min, Wenckebach periodicity (WB), and His-ventricular (H-V) conduction time at 150,180 , and 200 beats $/ \mathrm{min}$. Corrected sinus node recovery time (CSNRT) was measured by atrial pacing with the high right atrial electrode at three different heart rates above the spontaneous sinus rate of 150 ,

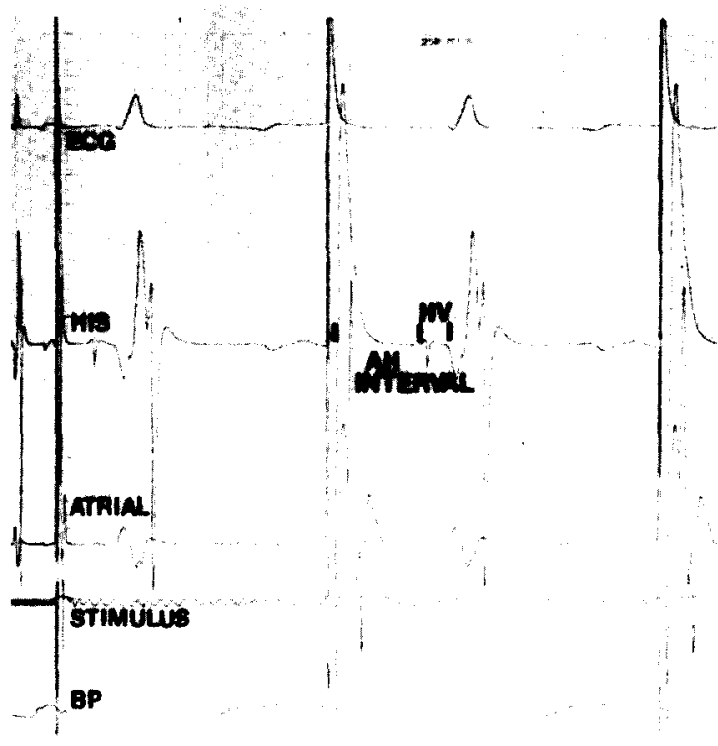

Fig 1. Simultaneous surface ECG (lead II), Hisbundle electrogram (showing A-H and $\mathrm{H}-\mathrm{V}$ intervals), and atrial electrogram recorded at paper speed of $250 \mathrm{~mm} / \mathrm{sec}$ during atrial pacing (stimulus artifact is also shown).

180 , and 200 beats $/ \mathrm{min}$ for 30 seconds with a one minute rest between each pacing period. Sinus node recovery time was determined as the time from the last paced $P$ wave to the first sinus escape beat seen on the atrial electrogram. Corrected sinus node recovery time was then calculated as the sinus node recovery time minus the pre-pacing, sinus P-P interval. The longest recovery time at the three pacing rates was recorded as the corrected sinus node recovery time. ${ }^{13}$

The A-H interval and the $\mathrm{H}-\mathrm{V}$ interval were recorded from the His-bundle electrogram at a paper speed of 250 $\mathrm{mm} / \mathrm{s}$. The A-H interval was measured from the beginning of atrial activity to the beginning of the His potential, and the $\mathrm{H}-\mathrm{V}$ interval as the time from the beginning of the His potential to the beginning of the ventricular electrogram in the His-bundle recording. All dogs were paced at three different rates: 150,180 , and 200 beats/min, with both A-H and $\mathrm{H}-\mathrm{V}$ intervals recorded following 30 seconds of pacing.

Wenckebach periodicity was determined by atrially pacing from sinus rhythm and decreasing the paced cycle length by $10 \mathrm{msec}$ every ten beats until the Wenckebach phenomenon occurred. The cycle length at which the Wenckebach phenomenon first occurred was recorded as WB. ${ }^{14}$

Atrial pacing was achieved with a Grass $\mathrm{S} 88$ stimulator, using a square wave impulse with a duration of $2 \mathrm{msec}$. The stimulating current used was three times the diastolic threshold determined at the beginning of each experiment.

The data were analyzed using non-paired Students $t$ test after an analysis of variance. All $\boldsymbol{P}$ values are reported using the Bonferroni correction for multiple comparisons when indicated. The data for A-H conduction were compared to chloralose; for the other measurements, between-group comparisons for inhalation agents were made. The interrelationships between the A-H intervals were further examined 
Table 1. Effects of Anesthetic Agents on Mean Blood Pressure, Heart Rate, and CSNRT

\begin{tabular}{lccll}
\hline & Chloralose & Halothane & Enflurane & 1softurane \\
\hline Mean BP $(\mathrm{mm} \mathrm{Hg})$ & $90 \pm 20$ & $76 \pm 16$ & $61 \pm 13 \dagger$ & $79 \pm 13$ \\
HR (beats $/ \mathrm{min}$ ) & $119 \pm 19$ & $105 \pm 10^{*}$ & $97 \pm 6 \dagger$ & $99 \pm 9 \dagger$ \\
CSNRT (msec) & $102 \pm 52$ & $70 \pm 27$ & $71 \pm 59$ & $84 \pm 52$ \\
\hline
\end{tabular}

Abbreviations: BP, blood pressure; HR, heart rate.

NOTE: All values are mean \pm standard deviation.

* $P<.05$ compared to chloralose.

$\dagger P<.001$ compared to chloralose.

by profile analysis. Profile analysis is a combination of tests which in this experiment examines for a main effect for differences among anesthetics, a main effect for changes in heart rate, and an interaction between anesthetics and heart rate. The interactive effect or test for parallelism is analogous to a repeated measures analysis of variance. ${ }^{\text {is }}$

\section{RESULTS}

The heart rate and blood pressure of the four groups taken after the 30-minute stabilization period are shown in Table 1, along with the corrected sinus node recovery times. There are no differences in corrected sinus node recovery times among the three inhalational agents. The measurements for A-H150, A-H180, A-H200, WB, H-V150, H-V180, and H-V200 are shown in Table 2. Five of the dogs anesthetized with enflurane exhibited the Wenckebach phenomenon when atrially paced at 180 beats/min. In these dogs, the A-H interval recorded was the interval immediately prior to the dropped beat, as this is the longest $\mathrm{A}-\mathrm{V}$ nodal conduction for this heart rate. This phenomenon did not occur with halothane or isoflurane. All results are compared with chloralose. There was no difference in the A-H interval at the slowest heart rate between the inhalational agents and chloralose. At higher paced rates of 180 and 200 beats/min, A-H intcrvals in those animals receiving enflurane anesthesia were significantly prolonged when compared to those receiving chloralose anesthesia (Fig 2). Further analysis of the A-H intervals using profile analysis demonstrated both a main and interactive effect when animals receiving enflurane are compared with those receiving chloralose. In addition, an interactive effect was demonstrated when the A-H intervals in animals receiving halothane are compared with those receiving chloralose $(P=.045)$. This suggests that the two slopes of the lines comparing the increase in A-H interval in animals receiving halothane and those receiving chloralose are not parallel as the heart rate is increased. The Wenckebach cycle length (WB) was prolonged in those dogs anesthetized with enflurane and halothane, but not isoflurane when compared with chloralose.

\section{DISCUSSION}

This study compared the effects of the inhalation agents halothane, enflurane, and isoflurane on A-V conduction, with reference to chloralose, an anesthetic which has minimal effects on $\mathrm{A}-\mathrm{V}$ nodal function. ${ }^{11}$ Atrioventricular conduction becomes prolonged with increasing heart rate ${ }^{16}$; therefore, it is important to determine $\mathrm{A}-\mathrm{H}$ and $\mathrm{H}-\mathrm{V}$ intervals at different, paced heart rates. In this way, comparisons at similar and increasing heart rates can be examined. This study did not attempt to determine the exact mechanisms responsible for alterations in $\mathrm{A}-\mathrm{V}$

Table 2. Effects of Anesthetic Agents on WB, A-H, and H-V Intervals (msec)

\begin{tabular}{|c|c|c|c|c|}
\hline & Chloralose & Halothane & Enflurane & Isoflurane \\
\hline WB & $247 \pm 28$ & $283 \pm 39 *$ & $306 \pm 41 t$ & $264 \pm 28$ \\
\hline A-H 150 & $89 \pm 24$ & $96 \pm 27$ & $110 \pm 46$ & $91 \pm 16$ \\
\hline A-H 180 & $96 \pm 27$ & $110 \pm 28$ & $200 \pm 104 t$ & $106 \pm 21$ \\
\hline A-H 200 & $104 \pm 33$ & $136 \pm 40$ & $256 \pm 148 t$ & $131 \pm 41$ \\
\hline$H-V 150$ & $36 \pm 4$ & $36 \pm 6$ & $35 \pm 3$ & $39 \pm 9$ \\
\hline$H-V 180$ & $36 \pm 5$ & $35 \pm 5$ & $35 \pm 3$ & $38 \pm 10$ \\
\hline H-V 200 & $36 \pm 6$ & $39 \pm 10$ & $34 \pm 3$ & $38 \pm 10$ \\
\hline
\end{tabular}

NOTE: All values are means \pm standard deviation.

$* P<.05$ compared to chloralose.

$\dagger P<.001$ compared to chloralose. 
Fig 2. Change in A-H interval with increasing paced heart rate in dogs undergoing halothane, onflurane, isoflurane. and chloralose anesthesia. All values are mean \pm SEM.

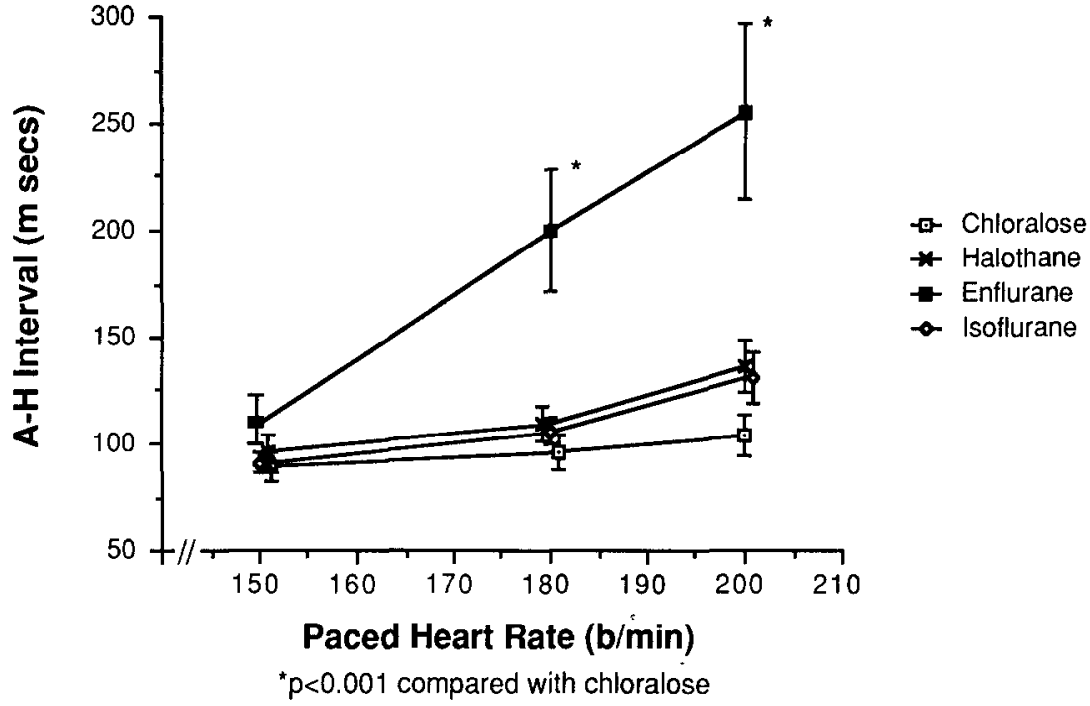

conduction, but rather to determine the effects of the inhalational agents as they may be used in the clinical setting, ie, without autonomic blockade.

Enflurane impaired $\mathrm{A}-\mathrm{V}$ conduction and refractoriness when compared with chloralose anesthesia. This effect of enflurane on the A-V node was demonstrated by a greater prolongation of the A-H interval with enflurane and an increased cycle length at which Wenckebach periodicity occurred. Evidence was also found that halothane impairs $\mathrm{A}-\mathrm{V}$ refractoriness as shown by the increased cycle length at which Wenckebach periodicity occurred. Although there was no change in A-H interval when animals anesthetized with halothane were compared with chloralose, profile analysis demonstrated that a significant interactive effect occurred $(P=.045)$. This suggests that the rate of change of A-H interval with increasing heart rate is not the same when the two drugs are directly compared. There was no evidence from this study that isoflurane affected $\mathrm{A}-\mathrm{V}$ conduction.

Wenckebach periodicity is a different measurement and correlates with other measurements of $\mathrm{A}-\mathrm{V}$ node refractoriness. ${ }^{17}$ The increase in Wenckebach cycle length seen with halothane and enflurane shows that the refractory period of the A-V node is prolonged compared with chloralose anesthesia.

In this study, enflurane produced a greater decrease in blood pressure than chloralose or the other inhalational agents. This is in agreement with its known direct effects on myocardial con- tractility ${ }^{18}$ and its indirect effects mediated by suppression of the baroreceptor reflex. ${ }^{19}$ This is unlikely to have caused the prolongation of the A-H interval or the increase in Wenckebach cycle length, as within each anesthetic group there was no correlation between blood pressure and $\mathrm{A}-\mathrm{H}$ interval or blood pressure and Wenckebach cycle length. With enflurane the results were as follows: BP $v$ A-H $150\left(r^{2}=.13, P>.2\right)$; BP $v$ A-H $180\left(r^{2}=.02, P>.6\right)$; BP $v$ A-H 200 $\left(r^{2}=.08, P>.3\right)$; BP, $v$ WB $\left(r^{2}=.06 P>.4\right)$.

Previous investigators have examined changes in A-V conduction produced by the inhalational anesthetics using either dose-related changes with increasing anesthetic concentrations $^{7-9}$ or by determining changes from the awake state in chronically instrumented animals. ${ }^{10}$ Differing results have been reported for the various agents depending on the model studied; the results for these experiments have been similar, but they have not been in total agreement.

The essential findings of the previous studies are summarized in Table 3. In none of these studies was Wenckebach periodicity measured. Taken collectively, three early, single-agent, dose-response studies suggested that enflurane may have a greater depressant effect on A-V conduction than the other inhalational agents. ${ }^{7-9}$ However, this was not seen in the later study of Atlee et al when a conscious control state was used. ${ }^{10}$ Using chronically instrumented dogs, they found that both enflurane and halothane produced a similar prolongation of the A-H 
Table 3. Previous Studies of Anesthetic Agents and A-V Conduction

\begin{tabular}{|c|c|c|c|c|c|c|c|c|}
\hline \multirow[b]{2}{*}{ Date } & \multirow[b]{2}{*}{ Author } & \multirow[b]{2}{*}{ Model } & \multirow{2}{*}{$\begin{array}{l}\text { Control } \\
\text { Comparison }\end{array}$} & \multirow{2}{*}{$\begin{array}{l}\text { Anesthetic } \\
\text { Concentration } \\
\text { MAC Equivalent }\end{array}$} & \multicolumn{2}{|c|}{$\Delta \mathrm{A}-\mathrm{H}$ Interval } & \multirow[b]{2}{*}{$\Delta H-V$ Interval } & \multirow[b]{2}{*}{$\triangle \mathrm{BP}$} \\
\hline & & & & & Basal HR & 200 beats $/ \mathrm{min}$ & & \\
\hline \multirow[t]{2}{*}{1977} & Atlee \& Alexander ${ }^{7}$ & Acute & Hal 1.25 MAC & $2.00 \mathrm{MAC}$ & $\leftrightarrow$ & $\leftrightarrow$ & $\uparrow$ & - \\
\hline & & & & $2.75 \mathrm{MAC}$ & $\uparrow$ & $\leftrightarrow$ & $\uparrow \uparrow$ & - \\
\hline \multirow[t]{2}{*}{1977} & Atlee \& Rusy ${ }^{8}$ & Acute & Enfl $1.0 \mathrm{MAC}$ & $1.5 \mathrm{MAC}$ & $\uparrow$ & $\uparrow$ & $\leftrightarrow$ & - \\
\hline & & & & 2.0 MAC & $\uparrow$ & $\uparrow \uparrow$ & $\leftrightarrow$ & - \\
\hline \multirow[t]{2}{*}{1979} & Blitt et $\mathrm{al}^{9}$ & Acute & Isof $1.25 \mathrm{MAC}$ & $2.0 \mathrm{MAC}$ & $\leftrightarrow$ & $\leftrightarrow$ & $\leftrightarrow$ & $40 \% \downarrow$ \\
\hline & & & & $2.5 \mathrm{MAC}$ & $\leftrightarrow$ & $\leftrightarrow$ & $\leftrightarrow$ & $42 \%$ \\
\hline \multirow[t]{9}{*}{1986} & Atlee et $a 1^{10}$ & Chronic awake & Awake & Hal 1.2 & $\uparrow$ & - & $\uparrow$ & $*$ \\
\hline & & & & Hal 1.7 & $\uparrow$ & - & $\uparrow$ & $15 \% \downarrow$ \\
\hline & & & & Hal 2.3 & $\uparrow$ & - & $\uparrow$ & $35 \% \downarrow$ \\
\hline & & & & Enfl 1.2 & $\uparrow$ & - & $\uparrow$ & $*$ \\
\hline & & & & Enfl 1.7 & $\uparrow$ & - & $\uparrow \uparrow$ & $27 \%$ \\
\hline & & & & Enfl 2.3 & $\uparrow$ & - & $\uparrow \uparrow$ & $44 \% \downarrow$ \\
\hline & & & & Isof 1.2 & $\leftrightarrow$ & - & $\uparrow$ & $*$ \\
\hline & & & & Isof 1.7 & $\uparrow$ & - & $\uparrow$ & $22 \% \downarrow$ \\
\hline & & & & Isof 2.3 & $\uparrow$ & - & $\uparrow$ & $41 \% \downarrow$ \\
\hline
\end{tabular}
1.2 MAC.

Abbreviations: Hal, halothane; Enfl, enflurane; Isof, isoflurane.

Symbols: $\leftrightarrow$, no change from control; $\uparrow$, increase compared with control; $\uparrow \uparrow$, further increase compared to control; *, $\Delta$ from Anes

interval. In that study, however, basal heart rates were only measured as spontaneous heart rates, and the effect of higher paced heart rates was not investigated; thus, the results of the present study and that of Atlee et $\mathrm{al}^{10}$ are not directly comparable.

The use of chloralose in the present experiment allowed for comparison of the effects of equivalent anesthetic concentrations of the inhalational agents to another anesthetic (which does not affect $\mathrm{A}-\mathrm{V}$ conduction or $\mathrm{A}-\mathrm{V}$ refractoriness). ${ }^{11}$ This was useful as it had been suggested that the changes in $\mathrm{A}-\mathrm{V}$ conduction with the inhalational anesthetic agents were due to the anesthetic state rather than the individual agents. ${ }^{10}$ Possible mechanisms for the changes in A-V conduction and refractoriness include both a direct effect of the agent and an indirect effect due to a decrease in sympathetic tone due to that agent. Differentiation of these two mechanisms was not possible with this experimental model. It is possible that the different experimental model of an open chest animal rather than a closed chest one as described in previous studies may also influence some of the results. It is apparent from the data presented in this experiment that enflurane has a more depressant effect on A-V conduction and refractoriness than either isoflurane or halothane at equipotent concentrations
$(1.5 \times$ MAC), levels that are likely to be used clinically. In addition, there have been no previous data comparing equivalent anesthetic concentrations of the inhalational agents at increasing paced heart rates. The results from the present experiment at a heart rate of 150 beats/ min demonstrates that there is no difference in A-H conduction when the inhalational agents are compared to chloralose. Impaired A-H conduction in enflurane-anesthetized animals is only apparent at increased heart rates when conduction through the node is already prolonged.

Sinus node function is difficult to assess in the intact animal as evidenced by the wide standard deviations in the data presented. Previous in vitro studies revealed that halothane, enflurane, and isoflurane caused approximately equal depression of sinus node function (as shown by a decrease in the slope of phase 4 and phase 0 depolarization and a decrease in the action potential duration). ${ }^{5}$ The depression of sinus node function seen in vivo is easily reversed by epinephrine. The effects of chloralose on sinus node function have not been documented, therefore only a within-group comparison of the inhalational agents was possible. Corrected sinus node recovery time is a measure of sinoatrial automaticity and function. ${ }^{20}$ Although corrected sinus node recovery time is prolonged by increas- 
ing heart rate, in the canine model the maximum prolongation occurs at a heart rate of 200 beats/ min. ${ }^{21}$ There are no data on corrected sinus node recovery time values in the awake dog. Information from dogs anesthetized with pentobarbital undergoing sinus node injury by crushing has demonstrated that corrected sinus node recovery time values increase from $104 \pm 13 \mathrm{msec}$ before sinus node injury to $359 \pm 34 \mathrm{msec}$ at a rate of 200 beats/min after sinus node injury. ${ }^{21}$ Clearly the values presented in the present experiment do not suggest any evidence of sinus node dysfunction at the concentrations used. Subtlc changes in sinus node function compared with the awake state, and autonomic influences on sinus node function in the presence of inhalational agents have not been reported.
In conclusion, these data suggest that when equipotent anesthetic concentrations of inhalational agents are compared in the canine model, enflurane has a more deleterious effect on A-V conduction and refractoriness than halothane or isoflurane. The difference between the inhalational agents when compared to chloralose anesthesia makes it unlikely that the anesthetic state is solely responsible for the changes observed. In addition, preliminary data on sinus node function at the same anesthetic concentration of inhalational agents does not suggest that any significant dysfunction occurs.

\section{ACKNOWLEDGMENT}

The authors acknowledge the assistance of Mr. Kenneth Guire, Department of Biostatistics, University of Michigan, with the statistical analysis of the presented data.

\section{REFERENCES}

1. Kapur PA, Bloor BC, Flacke WE, et al: Comparison of cardiovascular responses to verapamil during enflurane, isoflurane, or halothane anesthesia in dogs. Anesthesiology 61:156-160, 1984

2. Chelly JE, Rogers K, Hysing ES, et al: Cardiovascular effects of the interaction between calcium blocking drugs and anesthetics in chronically instrumented dogs. I. Verapamil and halothane. Anesthesiology 64:560-567, 1986

3. Rogers K, Hysing ES, Merin RG, et al: Cardiovascular effects of and interaction between calcium blocking drugs and anesthetics in chronically instrumented dogs. II. Verapamil, enflurane, and isoflurane. Anesthesiology 64:568-575, 1986

4. Atlec JL, Rusy BF: Halothane depression of A-V conduction studied by electrograms of the bundle of $\mathrm{His}$ in dogs. Anesth Analg 36:112-118, 1972

5. Bosnjak ZJ, Kampine JP: Effects of halothane, enflurane, and isoflurane on the SA node. Anesthesiology 58:314-321, 1983

6. Hickey RF, Eger EI: Circulatory pharmacology of inhaled anesthetics, in Miller RD (ed): Anesthesia: 2nd Edition. New York, Churchill-Livingstone, 1986, pp 649666

7. Atlee JL, Alexander SC: Halothane effects on conductivity of the AV node and His-Purkinje system in the dog. Anesth Analg 56:378-386, 1977

8. Atlee JL, Rusy BF: Atrioventricular conduction times and atrioventricular nodal conductivity during enflurane anesthesia in dogs. Anesthesiology 47:498-503, 1977

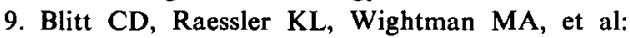
Atrioventricular conduction in dogs during anesthesia with isoflurane. Anesthesiology 50:210-212, 1979

10. Atlee JL, Brownlee MS, Burstrom RE: Conscious state comparisons of the effects of inhalation anesthetics on specialized atrioventricular conduction times in dogs. Anesthesiology 64:703-710, 1986
11. Marullaz PD, Delaigue RF, Gueorguiev G, et al: Influence of chloralose and pentobarbitone anesthesia on atrioventricular conduction in dogs. Br J Pharmacol 77:309317,1982

12. Eger EI: Anesthetic Uptake and Action. Baltimore, Williams and Wilkins, 1974, p 5

13. Narula OS, Samet P, Javier RP: Significance of the sinus-node recovery time. Circulation 45:140-158, 1972

14. Narula OS, Runge M: Accommodation of A-V nodal conduction and fatigue phenomenon in the HisPurkinje system, the conduction system of the heart, in Wellens HJ, Lie KI, Janse MJ (eds): The Conduction System of the Heart: Structure, Function, and Clinical Implications. Philadelphia, Lea and Febiger, 1976, pp 529-544

15. Morrison DF: Multivariate Statistical Methods. New York, McGraw-Hill, 1967, pp 186-197

16. Damato AN, Lau SH, Bobb GA, et al: Recording of A-V nodal activity in the intact dog heart. Am Heart $\mathbf{J}$ 80:353-366, 1970

17. Bisset JK, Kane JJ, de Soyza N, et al: Electrophysiological significance of rapid atrial pacing as a test of atrioventricular conduction. Cardiovasc Res 9:593-599, 1975

18. Brown BR, Crout JR: A comparative study of the effects of five general anesthetics on myocardial contractility. Anesthesiology 34:236-245, 1971

19. Morton M, Duke PC, Ong B: Baroreflex control of heart rate in man during enflurane and enflurane-nitrous oxide anesthesia. Anesthesiology 52:221-223, 1980

20. Reiffel J $\Lambda$ : Principles and applications of electrophysiologic testing of sinus node function. Cardiovasc Med 4:97-111, 1979

21. Chadda KD, Banka VS, Bodenheimer MM, et al: Corrected sinus node recovery time. Experimental physiologic and pathologic determinants. Circulation 51:797-801, 1975 